\title{
Structural intensity analysis of a large container carrier under harmonic excitations of propulsion system
}

\author{
Dae-Seung Cho ${ }^{1}$, Kyung-Soo Kim ${ }^{1}$ and Byung-Hwa Kim ${ }^{2}$ \\ ${ }^{1}$ Dept. of Naval Architecture and Ocean Engineering, Pusan National University, Korea \\ ${ }^{2}$ New Products R\&D Team, Daewoo Shipbuilding \& Marine Engineering Co., Ltd., Korea
}

\begin{abstract}
The structural intensity analysis, which calculates the magnitude and direction of vibrational energy flow from vibratory velocity and internal force at any point of a structure, can give information on dominant transmission paths, positions of sources and sinks of vibration energy. This paper presents a numerical simulation system for structural intensity analysis and visualization to apply for ship structures based on the finite element method. The system consists of a general purpose finite element analysis program MSC/Nastran, its pre- and post-processors and an in-house program module to calculate structural intensity using the model data and its forced vibration analysis results. Using the system, the structural intensity analysis for a 4,100 TEU container carrier is carried out to visualize structural intensity fields on the global ship structure and to investigate dominant energy flow paths from harmonic excitation sources to superstructure at resonant hull girder and superstructure modes.
\end{abstract}

KEYWORDS: Structural intensity; Finite element method; Ship structure; Container carrier.

\section{INTRODUCTION}

Understandably, the vibration criteria required by the ship owners are getting stricter, not only for the consideration of ship durability but for the more comfortable habitability of crew and passenger. For the reason, most of shipyards have carried out the conventional vibration analysis for low vibration design of ship structure using numerical methods such as finite element analysis. Its purpose is to predict vibratory amplitudes of global and local ship structures due to the excitation induced by propulsion system and ocean environment, and to evaluate whether the ship design satisfies the specified vibration criteria. However, in case that troublesome vibration is expected from the analysis, it is not easy to know how to effectively and rationally modify the structure design to reduce the troublesome vibratory response with only the predicted information on conventional natural frequencies, natural modes and vibratory responses of ship structure.

On the other hand, the structural intensity, which is the power flow per unit cross-sectional area in elastic medium and can be calculated from the vibratory velocity and the internal force of the structure due to certain excitations, can give information on the source power, the dominant transmission path and the dissipation mechanism of vibratory

Corresponding author: Dae-Seung Cho

e-mail:daecho@pusan.ac.kr energy. Since Noiseux (1970) introduced the measurement method of power flow in beams and plates using measured acceleration and wave equation, many studies have been carried out over the years to understand power flow phenomena in structures.

For examples, Pavic (1976), Fahy and Pierri (1977) and Verheij (1980) presented the measurement methods of vibration power flow using the measured vibratory amplitudes in frequency and/or time domain and the internal forces numerically estimated by finite difference method. The other measurement methods such as frequency response technique (Linjama and Lahti, 1992), near-field acoustical holography (Saijyou and Yoshikawa, 1996) and scanning laser vibrometer (Pascal et al, 2006) were also introduced. Analytical approaches to calculate structural intensity have been also carried out for the elastic vibration of thin cylindrical shells (Pavic, 1990 and Williams, 1991), the elastic vibration of uniform infinite beam and plate (Xu and Koss, 1995), the torsional vibration of solid and hollow cylindrical bars (Pan and Pan, 1998), and the in-plane vibration of rectangular plates (Farag and Pan, 1998). Structural intensity analysis using the finite element method (FEM) was also formulated by Hambric (1990) and Gavric and Pavic (1993). Using the FEM, structural intensity fields for frame and cylindrical shell structures (Alfredsson et al, 1996), composite plates with a hole ( $\mathrm{Xu}$ et al, 2004), stiffened plates (Xu et al, 2004) and box-girder structure (Lee and Cho, 2001). 
The structural intensity approach has been successfully used in the field of plate vibration to determine major vibration transmission paths. However, as best as we know, it is difficult to find studies on the structural intensity approach for global vibration of large ship structures.

In this paper, a numerical simulation system for analyzing and visualizing the structural intensity of thinwalled large and complex structures such as ship structure is presented. The system consists of an in-house computation program module to calculate structural intensity using the forced vibration analysis results and its model data, a general purpose finite element analysis program MSC/Nastran and its pre- and post-processors. Using the system, the structural intensity analysis for a 4,100 TEU container carrier based on the mode superposition method has been carried out in cases of the vertical force and moment excitations on main engine crankshaft, the excitation in vertical above propeller top and the longitudinal excitation on thrust block, which are the major excitations inducing the longitudinal vibration of the ship superstructure. From the analysis, the dominant vibratory energy flow paths from excitation sources to superstructure are evaluated.

\section{FORMULATION OF STRUCTURAL INTENSITY FOR SHIP STRUCTURE}

To treat structural intensity of ship structure using the finite element method, structural intensities in beam and shells which are fundamental elements of ship structure should be derived as functions of internal forces and moments, translational and angular displacements resulting from the forced vibration analysis.

The instantaneous intensity component is a timedependent vectorial quantity equal to the change of energy density in a given infinitesimal volume. Its $i$-th component in time domain can be generally defined as

$I_{i}(t)=-\sigma_{i j}(t) v_{j}(t), \quad i, j=1,2,3$,

where $\sigma_{i j}(t)$ is the component of the stress tensor at a point where $i$ represents the normal direction of the area and $v_{j}(t)$ is the velocity vector in the $j$-direction at time $t$.

For steady state vibrations, the instantaneous structural intensity lying along the centerline of a beam by integration of the structural intensity over the cross-section of the beam shown in Fig. 1 can be expressed as (Gavric and Pavic, 1993)

$I_{x}(t)=-\left(\dot{u} N_{x}+\dot{v} Q_{y}+\dot{w} Q_{z}+\dot{\theta}_{y} M_{y}+\dot{\theta}_{z} M_{z}+\dot{\theta}_{x} T_{x}\right)$

where $N_{x}, Q_{y}, Q_{z}, M_{y}, M_{z}, T_{x}$ represent axial force, shear forces, bending moments and torque, respectively. $\dot{u}, \dot{v}, \dot{w}$ and $\dot{\theta}_{y}, \dot{\theta}_{z}$ are translational and rotational velocities, respectively.
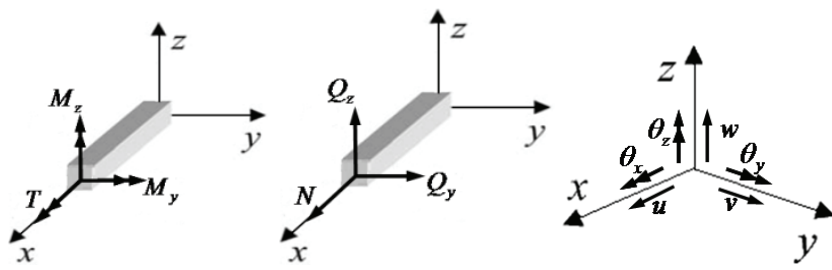

Fig. 1 Forces, moments and displacements for beam element.

The instantaneous intensity in case of the plate midsurface lying in the $\boldsymbol{x}-, \boldsymbol{y}$ - plane with the positive direction definition of internal forces and displacement shown in Fig. 2, the structural intensity can be expressed as

$I_{x}(t)=-\left(\dot{w} Q_{x}-\dot{\theta}_{y} M_{x}+\dot{\theta}_{x} T_{x}+\dot{u} N_{x}+\dot{v} N_{x y}\right)$

$I_{y}(t)=-\left(\dot{w} Q_{y}-\dot{\theta}_{y} T_{y}+\dot{\theta}_{x} M_{y}+\dot{u} N_{y x}+\dot{v} N_{y}\right)$

where $\quad M_{x}, M_{y}, T_{x}, T_{y}, N_{x y}, \quad N_{y x}, Q_{x}, Q_{y}, N_{x}, N_{y} \quad$ represent bending moments, twisting moments, in-plane shear forces, out-of-plane shear forces and in-plane axial forces, respectively. $\dot{u}, \dot{v}, \dot{w}$ and $\dot{\theta}_{x}, \dot{\theta}_{y}$ are translational and rotational velocities, respectively.

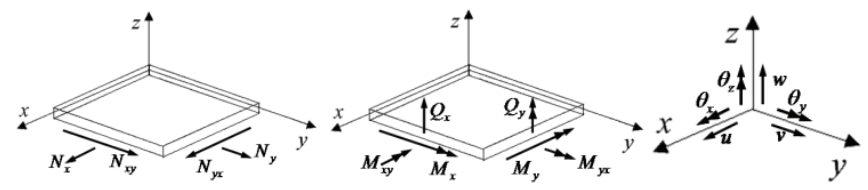

Fig. 2 Forces, moments and displacements for plate element.

The temporal mean of instantaneous structural intensity components represents the net energy flow through the structure. Hence, in a single frequency case, the time averaged structural intensity during the period in case of beam can be expressed as

$<I_{x}(\omega)>=\frac{j \omega}{2}\left(u^{*} N_{x}+v^{*} Q_{y}+w^{*} Q_{z}+\theta_{y}^{*} M_{y}+\theta_{z}^{*} M_{z}+\right.$

$\left.\theta_{x}^{*} T_{x}\right)$

where $j=\sqrt{-1}$ is the imaginary unit and the asterisk represents complex conjugate. The same quantities in case of plate can be expressed as

$$
\begin{aligned}
& <I_{x}(\omega)>=\frac{j \omega}{2}\left(w^{*} Q_{x}-\theta_{y}^{*} M_{x}+\theta_{x}^{*} T_{x}+u^{*} N_{x}+v^{*} N_{x y}\right) \\
& <I_{y}(\omega)>=\frac{j \omega}{2}\left(w^{*} Q_{y}-\theta_{y}^{*} T_{y}+\theta_{x}^{*} M_{y}+u^{*} N_{y x}+v^{*} N_{y}\right)
\end{aligned}
$$

Complex displacements and internal forces required for structural intensity computation can be computed by using a normal mode approach or a direct integration method. An outline of such a computation has been given in various books, research papers and theoretical manuals of conventional finite element analysis software. 


\section{SIMULATION SYSTEM FOR STRUCTURAL INTENSITY ANALYSIS AND VISUALIZATION}

For an efficient analysis of structural intensity fields and its visualization, in this study, a numerical simulation system has been developed. The simulation system consists of MSC/Patran for finite element modeling and visualization of structural intensity fields on the model, MSC/Nastran for a forced vibration analysis and in-house program named Nastran4Intensity.

The Nastran4Intensity has functions to read the information from MSC/Nastran input and output files such as geometry data, internal forces at element center and complex nodal displacement components at each node, and to calculate structural intensity components after transforming element forces into global coordinate system and evaluating displacements at element centroid using nodal displacement and element shape functions. Then, the program gives the calculated structural intensity vectors in the form of an element results files which can be visualized in MSC/Patran.

The flowchart of the structural intensity analysis and visualization using the system is shown in Fig. 3.

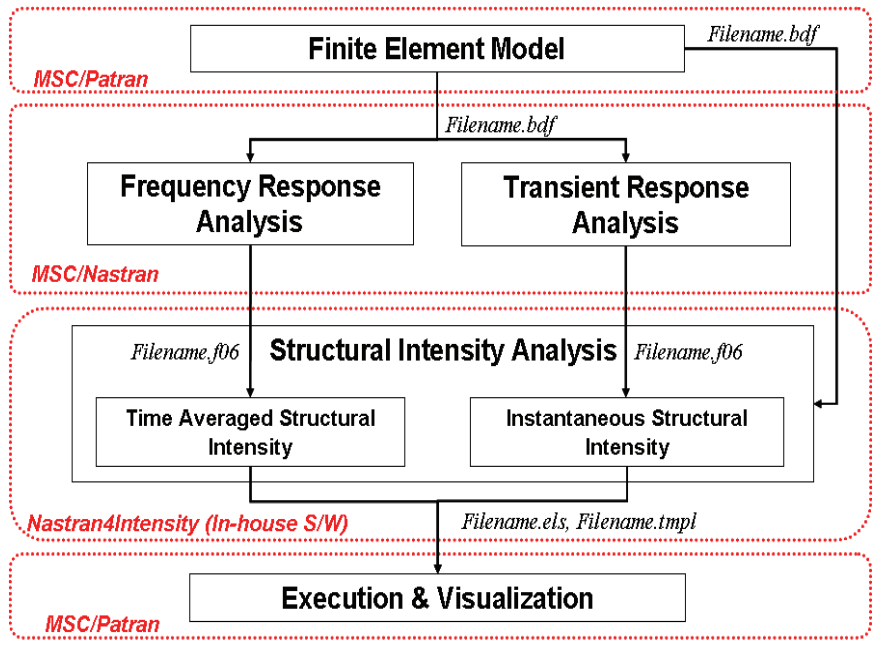

Fig. 3 Flowchart of structural intensity analysis and visualization.

\section{STRUCTURAL INTENSITY ANALYSIS FOR A CONTAINER CARRIER}

In this study, the free vibration analysis, the frequency response analysis and the structural intensity analysis for a 4,100 TEU container carrier have been carried out at its designed draft condition. The purposes are to investigate the transmission characteristics of the vibration energy from the various excitation sources of propulsion system causing vertical and longitudinal vibration of ship structure to the superstructure, and to identify dominant energy flow paths. The main particulars and the loading condition of the concerned vessel are represented in Table 1 .
Table 1 Main particulars and loading condition of the container carrier.

\begin{tabular}{|l|l|}
\hline Length (overall) & About 263.33m \\
\hline $\begin{array}{l}\text { Length } \\
\text { (between the perpendiculars) }\end{array}$ & $251.88 \mathrm{~m}$ \\
\hline Breadth (molded) & $32.20 \mathrm{~m}$ \\
\hline Draft (scantling) & $19.30 \mathrm{~m}$ \\
\hline Displacement & $67,746.5 t o n$ \\
\hline Main engine type & MAN B\&W 8K90MC-C \\
\hline $\begin{array}{l}\text { MCR } \\
\text { (maximum continuous rating) }\end{array}$ & $49,000 \mathrm{BHP} \times 104.00$ RPM \\
\hline $\begin{array}{l}\text { NCR } \\
\text { (normal continuous rating) }\end{array}$ & $44,712 \mathrm{BHP} \times 100.40$ RPM \\
\hline No. of propeller blade & $5 E A$ \\
\hline
\end{tabular}

\section{Numerical results of forced vibration analysis}

The major excitation sources inducing vertical and longitudinal vibration of ship structures are normally the vertical unbalance force and unbalance moment acting on the crankshaft of main diesel engine, the longitudinal thrust variation force acting on the thrust block of diesel engine and the vertical propeller surface force acting above the top of propeller. Using the modal superposition method, the longitudinal frequency response functions (FRF) at the navigation bridge deck of the superstructure and the vertical FRF at upper deck on the aft wall of superstructure due to the above excitations with the unit force $(1 \mathrm{kN})$ or moment $(1 \mathrm{kNm})$ are shown in Fig. 4. In the analysis, modal damping ratio was assumed to be 0.01 below $5 \mathrm{~Hz}, 0.03$ above $10 \mathrm{~Hz}$ with linear variation from $5 \mathrm{~Hz}$ to $10 \mathrm{~Hz}$.

\section{Numerical results of structural intensity analysis}

Among the frequencies representing resonant peak responses shown in Fig. 4, the natural frequency of 4-node vertical hull girder mode, $1.8193 \mathrm{~Hz}$, and the $1^{\text {st }}$ natural frequency of longitudinal superstructure mode, $5.1410 \mathrm{~Hz}$, have been chosen for investigating structural intensity fields of the ship structure. The mode shapes of the two frequencies are shown in Fig. 5.

The structural intensity fields of global and local ship structures at $1.8193 \mathrm{~Hz}$ in cases of the unit excitations of unbalance force and moment in vertical at the crankshaft of main engine, which are normally considered as major excitation sources of hull girder vibration of large merchant ship, are shown in Fig. 6 and Fig. 7, respectively. The results at $5.1410 \mathrm{~Hz}$ in cases of the unit excitations of propeller surface force and thrust variation, which are considered as major excitation sources of longitudinal vibration of ship superstructure, are shown in Fig. 8 and Fig. 9, respectively. In addition, the maximum structural intensities at global and local structures for the above excitations are represented in Table 2. 

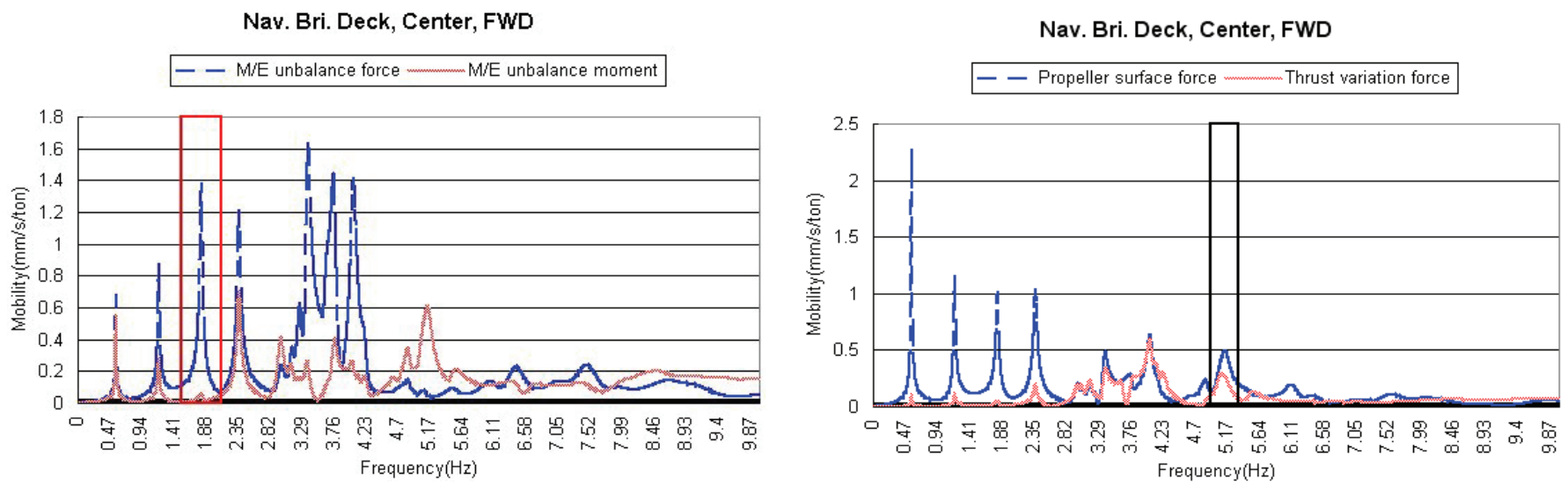

(a) Navigation bridge deck: Longitudinal direction.
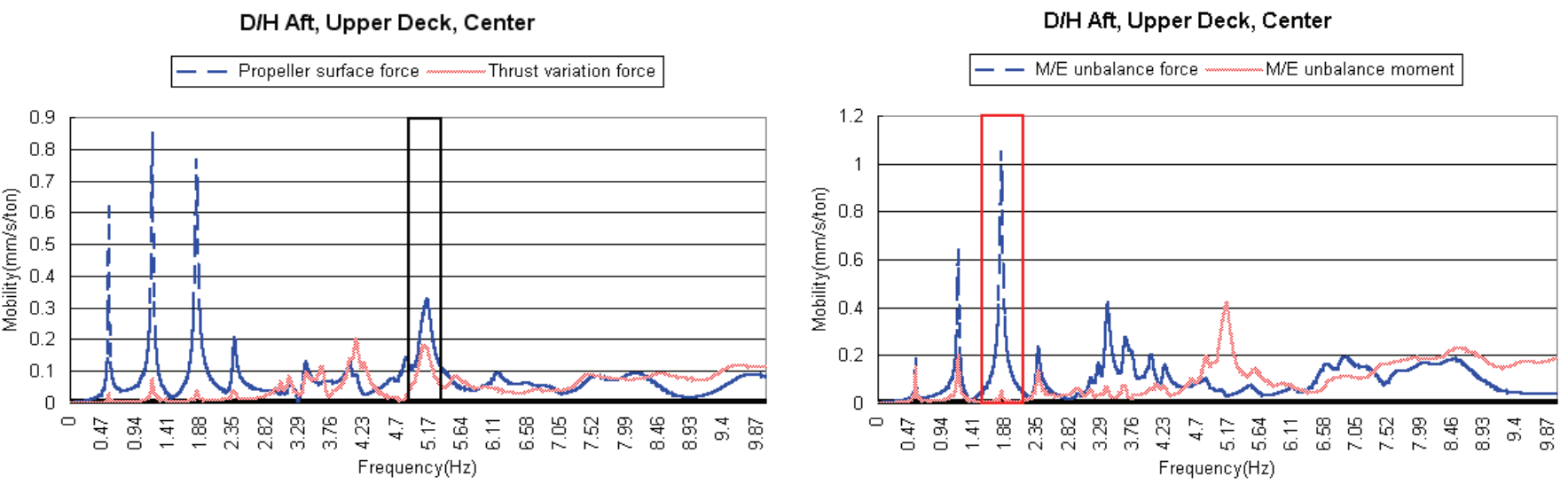

(b) Upper deck: Vertical direction.

Fig. 4 Frequency response functions of superstructure.

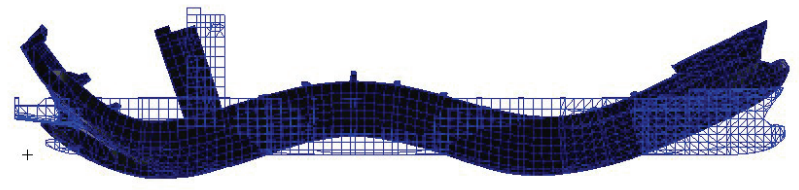

(a) Vertical 4-node mode of hull girder $(1.8193 \mathrm{~Hz})$.

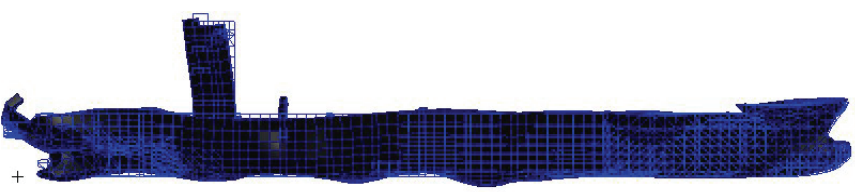

(b) 1st longitudinal mode of superstructure $(5.1410 \mathrm{~Hz})$.

Fig. 5 Two mode shapes of the ship at its scantling draft condition.

Table 2 Maximum structural intensity at global and local ship structures in cases of the unit excitations (Unit: $\mathrm{Watt} / \mathrm{m}$ ).

\begin{tabular}{|c|c|c|c|c|}
\hline Excitation frequency & \multicolumn{2}{|c|}{$1.8193 \mathrm{~Hz}$} & \multicolumn{2}{|c|}{$5.1410 \mathrm{~Hz}$} \\
\hline $\begin{array}{r}\begin{array}{r}\text { Excitation } \\
\text { type }\end{array} \\
\end{array}$ & Unbalance force & Unbalance moment & $\begin{array}{c}\text { Propeller surface } \\
\text { force }\end{array}$ & $\begin{array}{c}\text { Thrust variation } \\
\text { force }\end{array}$ \\
\hline Whole body & $9.24 \mathrm{E}-3$ & $5.12 \mathrm{E}-4$ & $9.69 \mathrm{E}-3$ & $8.23 \mathrm{E}-3$ \\
\hline Aft body & $9.24 \mathrm{E}-3$ & $5.12 \mathrm{E}-4$ & $9.69 \mathrm{E}-3$ & $8.23 \mathrm{E}-3$ \\
\hline Engine room & $9.24 \mathrm{E}-3$ & $5.12 \mathrm{E}-4$ & $6.78 \mathrm{E}-3$ & $3.08 \mathrm{E}-3$ \\
\hline Superstructure & $3.05 \mathrm{E}-3$ & $6.62 \mathrm{E}-5$ & $1.31 \mathrm{E}-3$ & $7.15 \mathrm{E}-4$ \\
\hline Internal longitudinal bulkhead & $9.24 \mathrm{E}-3$ & $3.90 \mathrm{E}-4$ & $3.19 \mathrm{E}-3$ & $1.09 \mathrm{E}-3$ \\
\hline Side shell in aft body & $9.07 \mathrm{E}-3$ & $3.91 \mathrm{E}-4$ & $9.69 \mathrm{E}-3$ & $2.39 \mathrm{E}-3$ \\
\hline Front wall of superstructure & $3.09 \mathrm{E}-3$ & $6.09 \mathrm{E}-5$ & $1.67 \mathrm{E}-3$ & $3.61 \mathrm{E}-4$ \\
\hline Aft wall of superstructure & $8.81 \mathrm{E}-3$ & 3.92E-4 & $1.27 \mathrm{E}-3$ & 3.69E-4 \\
\hline
\end{tabular}




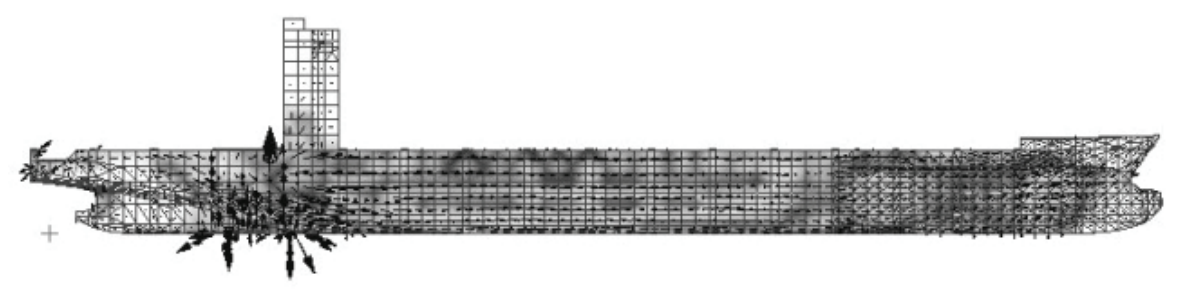

(a) Whole body

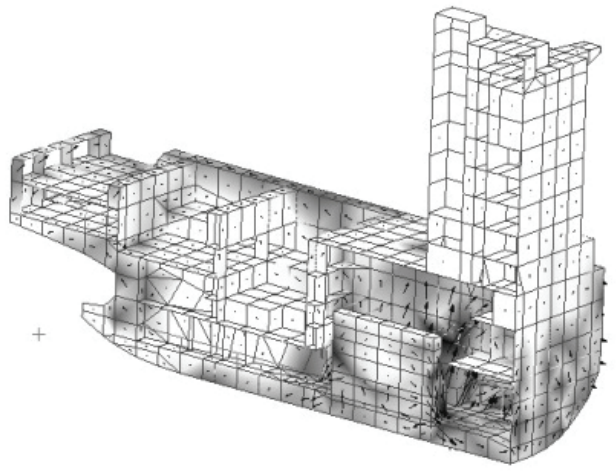

(b) Aft body

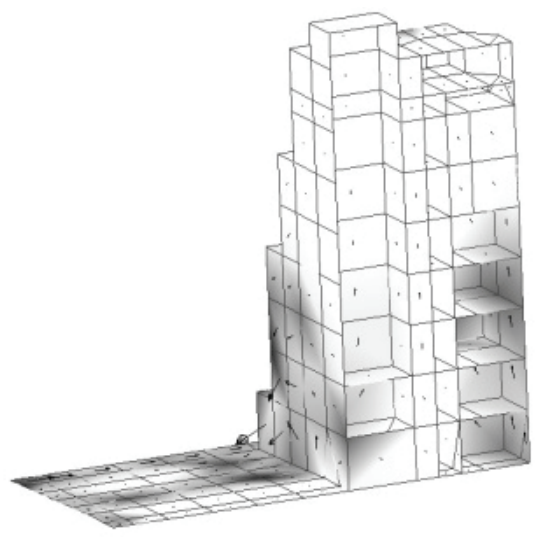

(d) Superstructure

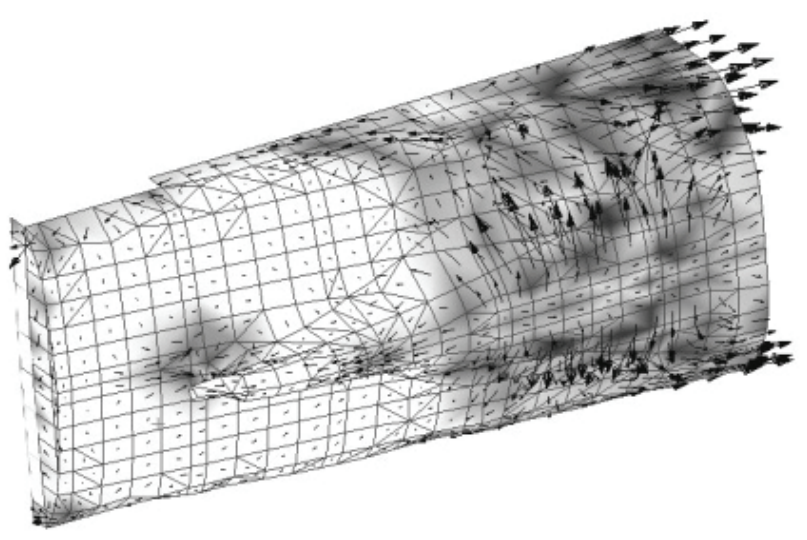

(f) Side shell in aft body

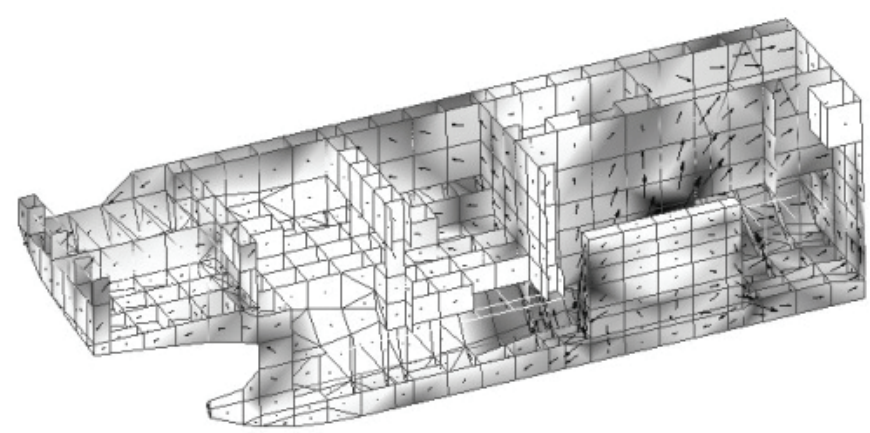

(c) Engine room

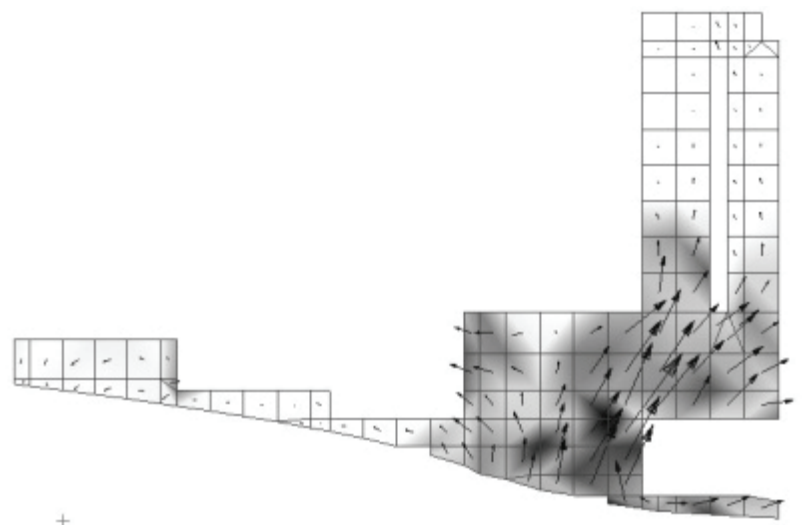

(e) Internal longitudinal bulkhead

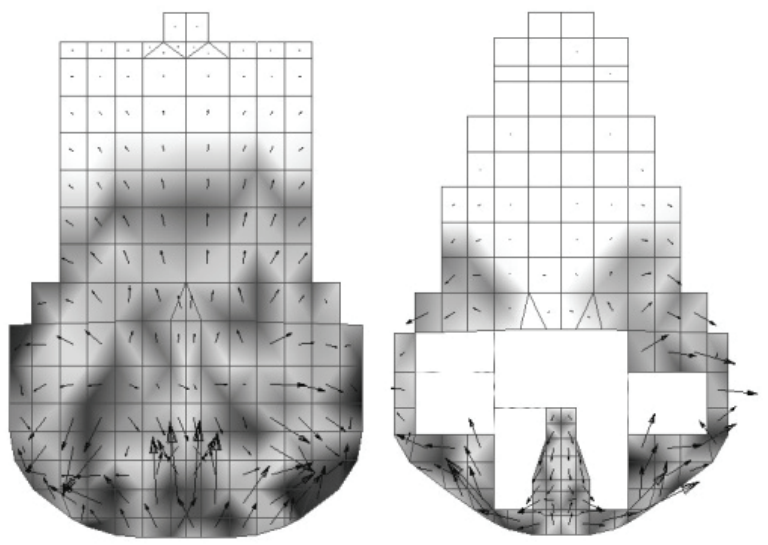

(g) Front and aft wall of superstructure

Fig. 6 Structural intensity at $1.8193 \mathrm{~Hz}$ in case of the vertical unit unbalance force excitation at the crankshaft of main engine. 


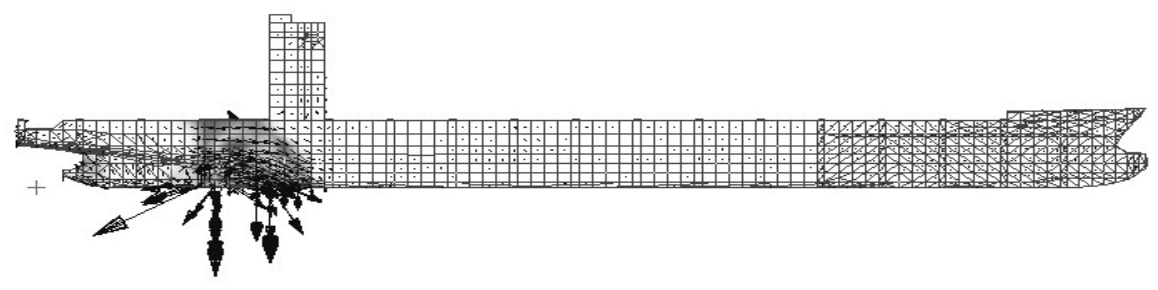

(a) Whole body

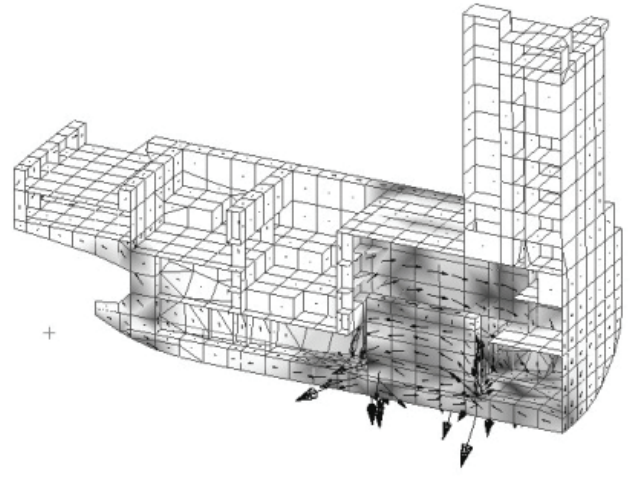

(b) Aft body

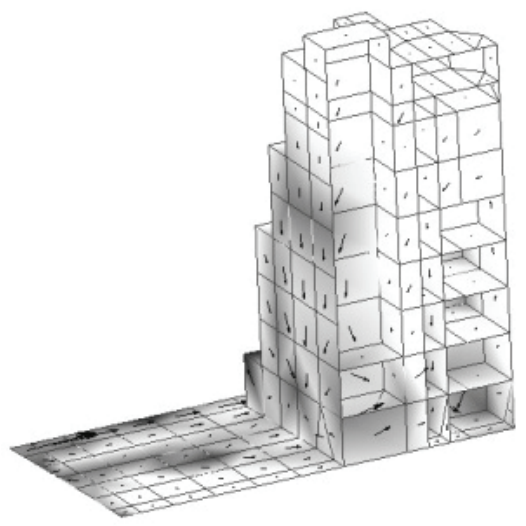

(d) Superstructure

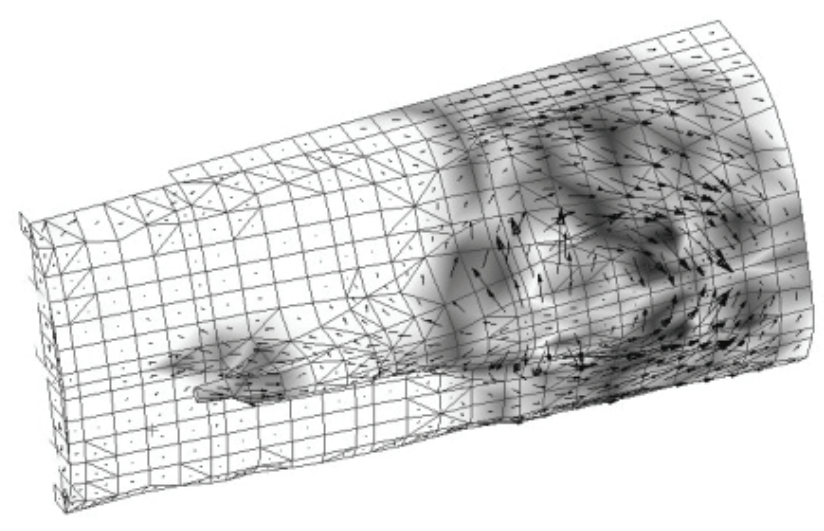

(f) Side shell in aft body

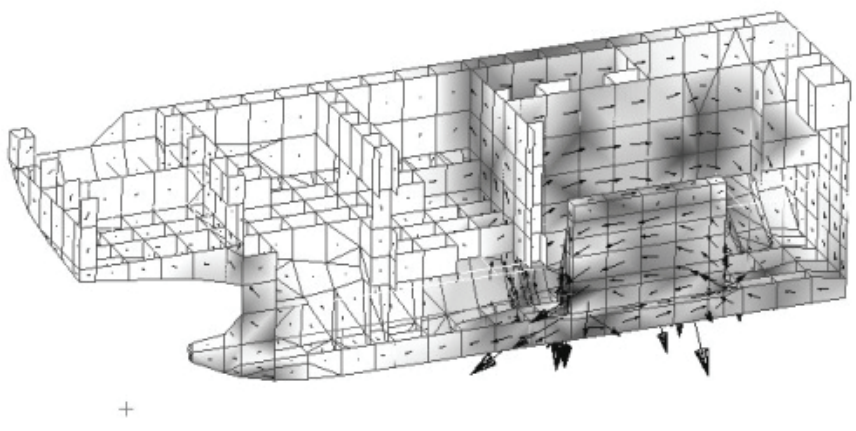

(c) Engine room

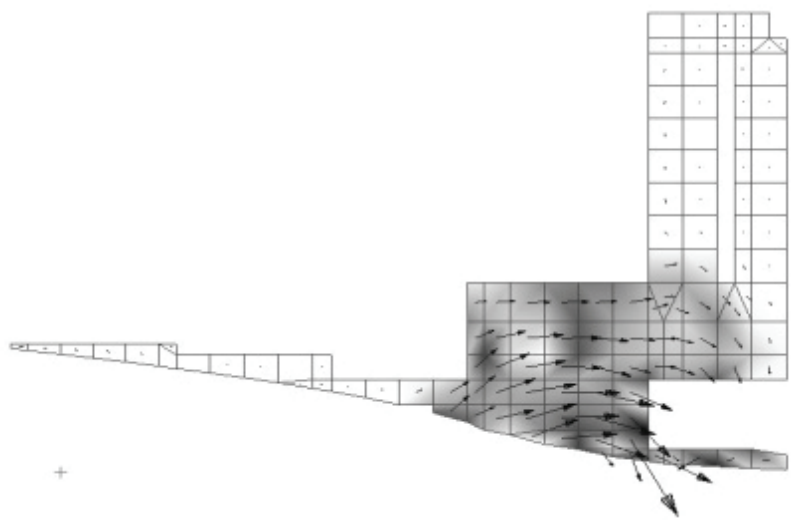

(e) Internal longitudinal bulkhead
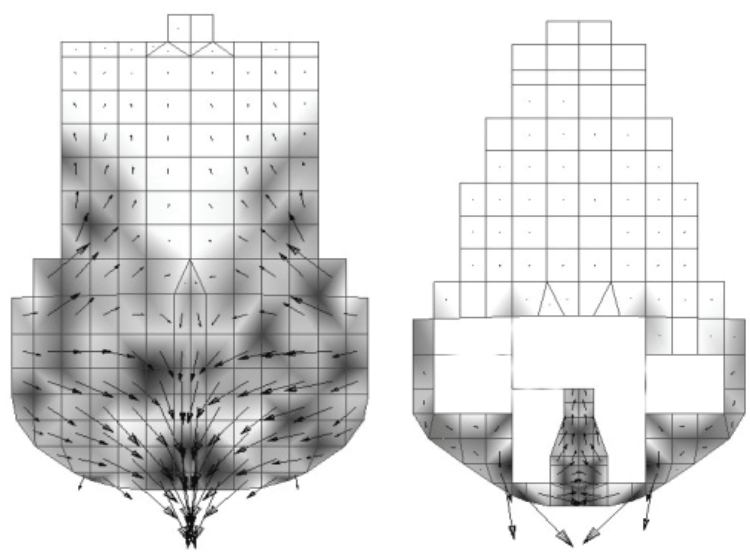

(g) Front and aft wall of superstructure

Fig. 7 Structural intensity at $1.8193 \mathrm{~Hz}$ in case of the vertical unit unbalance moment excitation at the crankshaft of main engine. 


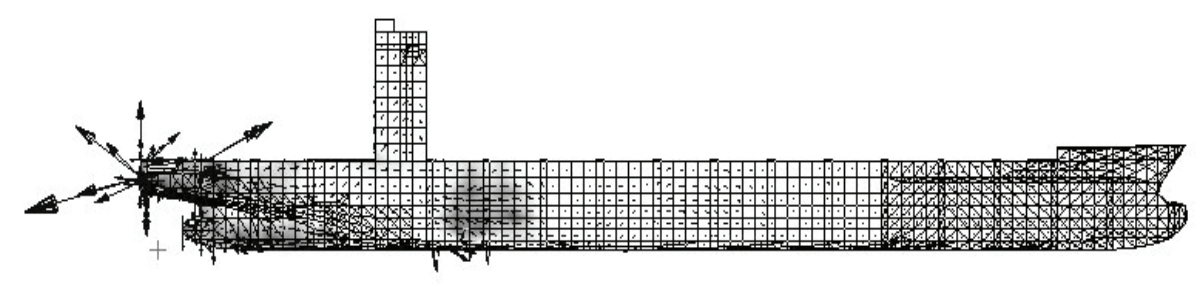

(a) Whole body

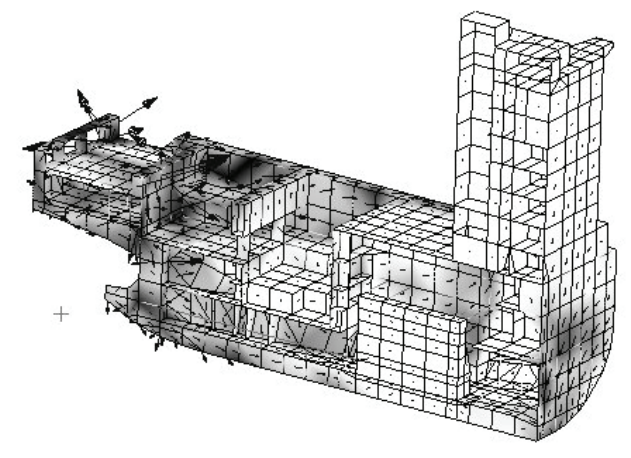

(b) Aft body

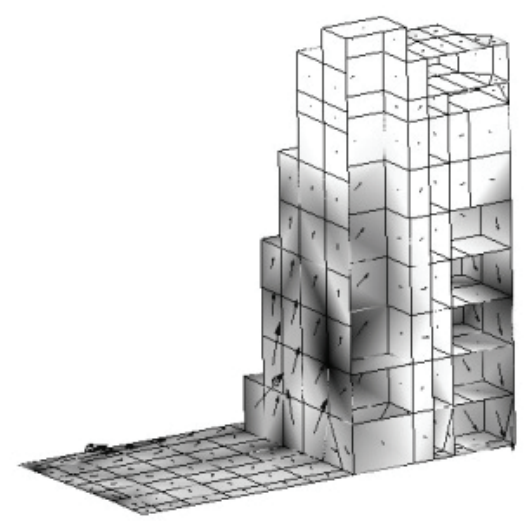

(d) Superstructure

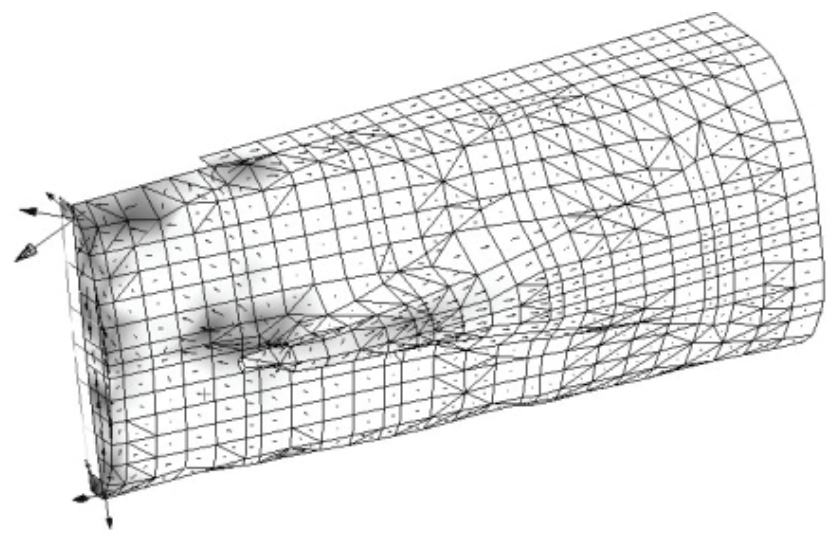

(f) Side shell in aft body

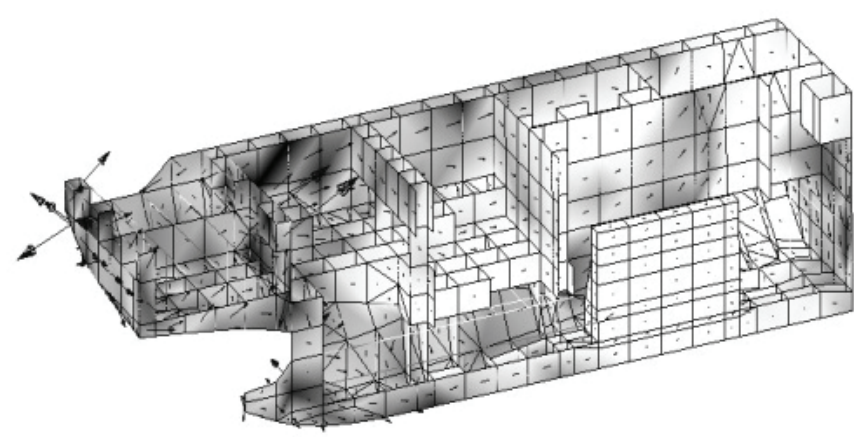

(c) Engine room

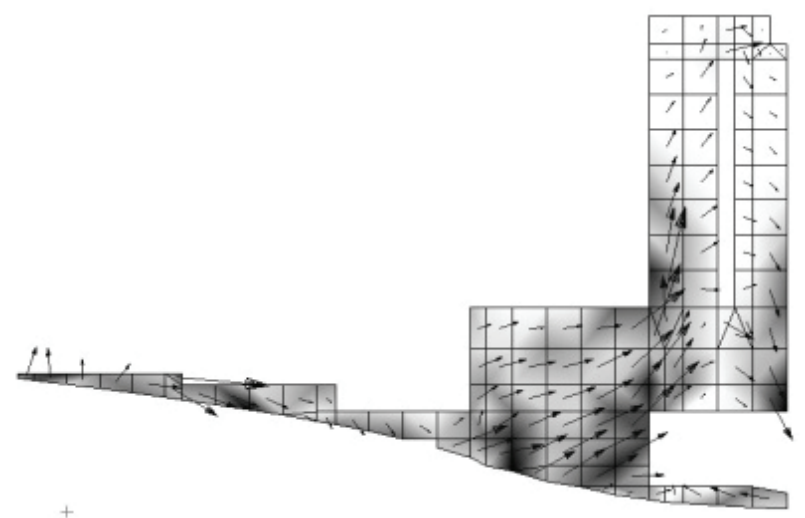

(e) Internal longitudinal bulkhead
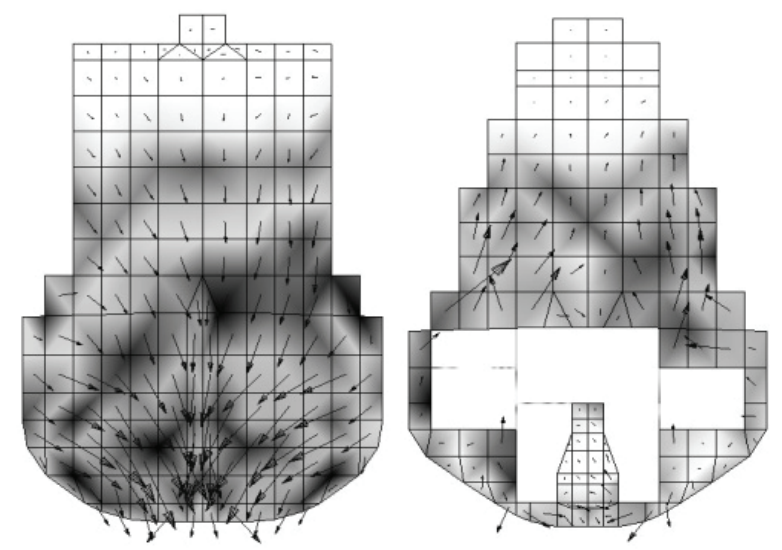

(g) Front and aft wall of superstructure

Fig. 8 Structural intensity at $5.1410 \mathrm{~Hz}$ in case of the unit propeller surface force excitation above propeller top. 


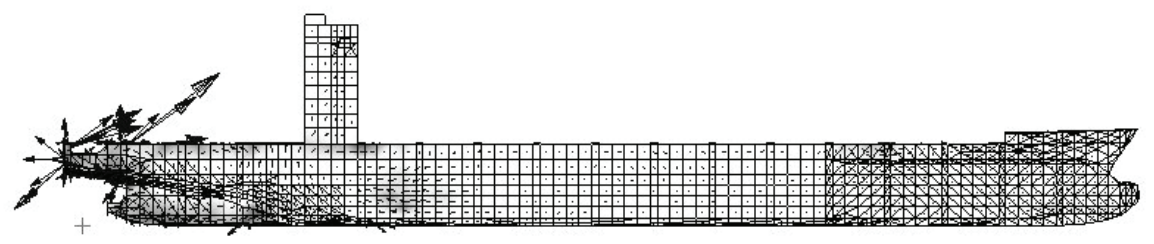

(a) Whole body

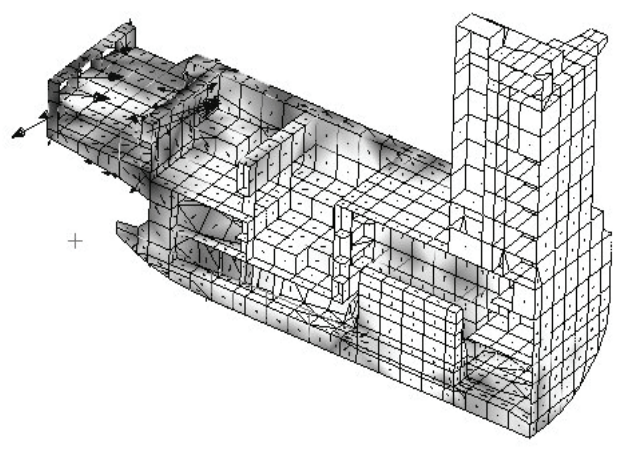

(b) Aft body

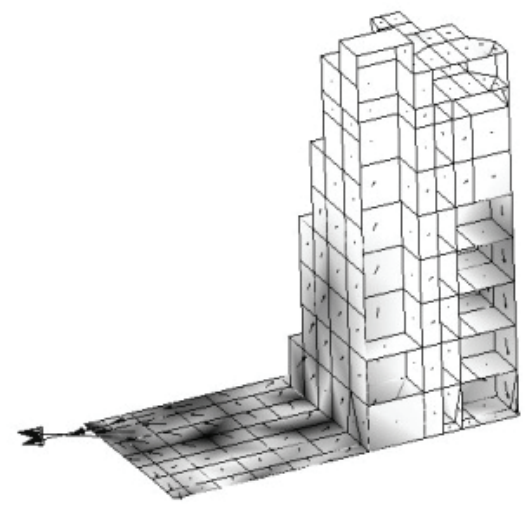

(d) Superstructure

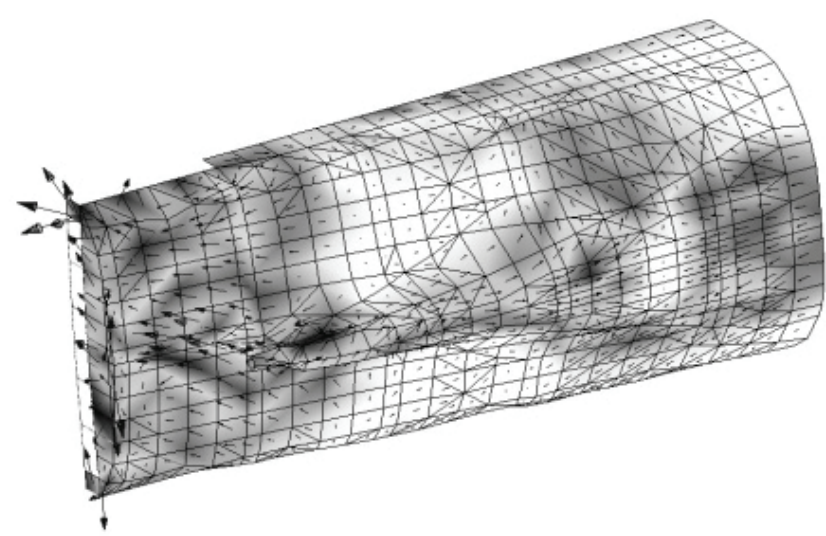

(f) Side shell in aft body

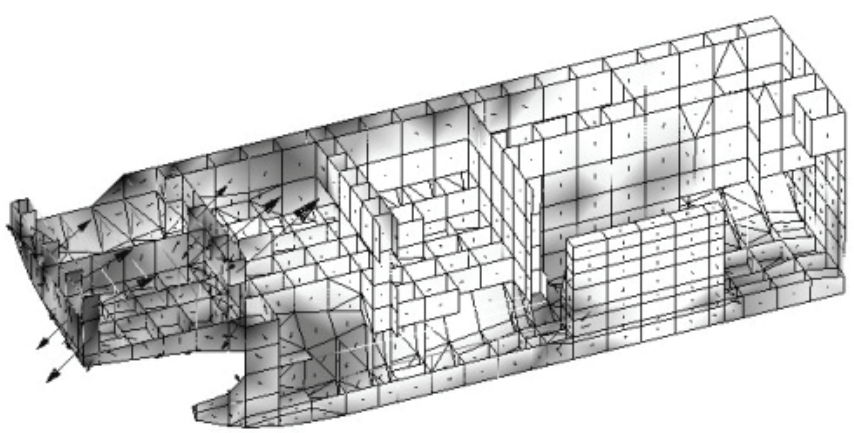

(c) Engine room

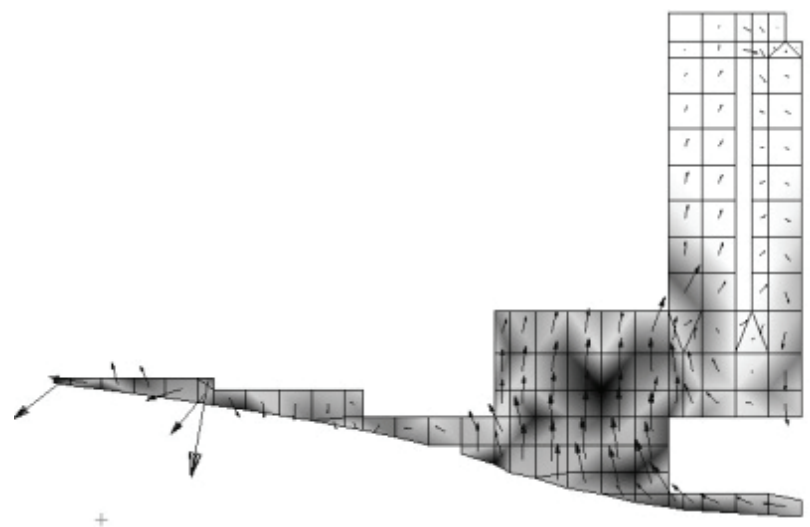

(e) Internal longitudinal bulkhead
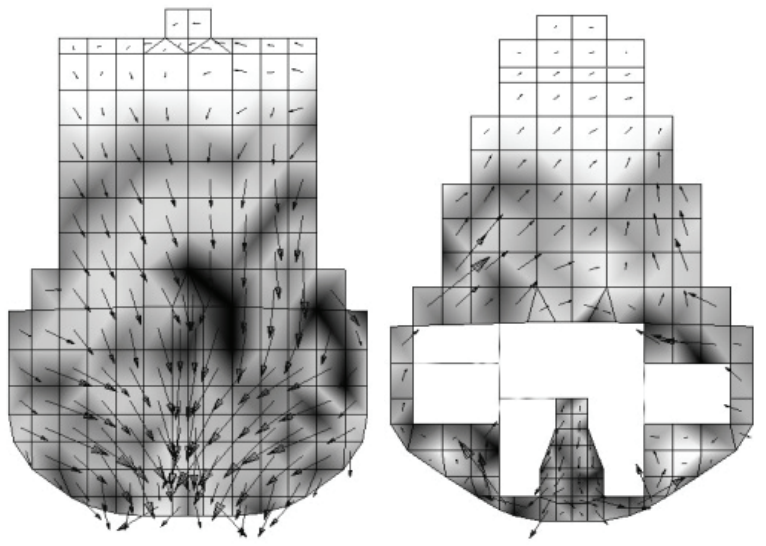

(g) Front and aft wall of superstructure

Fig. 9 Structural intensity at $5.1410 \mathrm{~Hz}$ in case of the unit thrust variation force excitation at thrust block. 


\section{DISCUSSIONS}

From the above analysis results for the container carrier, it can be seen that the vibratory energies flow from excitation sources to all the parts of ship structure but the magnitudes at holds and fore-body structures are less than those at aft body structures. Moreover, the vibratory energies in the aft body except the unbalance moment excitation flow from excitation sources to superstructure via side shell, tank top, longitudinal girder and internal longitudinal bulkhead of engine room. On the other hand, in case of the unbalance moment excitation, there is little energy propagation to superstructure. These phenomena can be known by analogy from the frequency response functions of superstructure where the peak response due to the unbalance moment is very small compared with the others as shown in Fig. 4.

In case of the unbalance force excitation, the maximum structural intensity is found at the internal longitudinal bulkhead of engine room, which is the main support structure of superstructure in longitudinal direction, and the energy at the structure flows to superstructure strongly. The magnitudes at side shell structure of aft body are quite large but almost energy flow is toward midship structure. The largest structural intensity in case of the propeller surface force excitation is found at the local stern structure due to its resonance. Except the part, the major energy flow path to superstructure is evaluated as the internal longitudinal bulkhead of engine room via double bottom and longitudinal girder structures of aft body, which is quite similar with the energy flow path in case of thrust variation force excitation. Hence, it is concluded that the most dominant energy path from the excitations by the propulsion system of this ship to superstructure is the internal longitudinal bulkhead of engine room.

\section{CONCLUSION}

In this paper, a numerical simulation system for structural intensity analysis and visualization was introduced with its theoretical background and simulation components. From the structural intensity analysis for a 4,100 TEU container carrier, it is validated that the simulation system can be effectively applied for the structural intensity analysis of global ship structure and its result visualization. Moreover, it is identified that the internal longitudinal bulkhead of engine room of the ship is one of the most dominant transmission paths of vibratory energy from the excitation sources such as unbalance force, propeller surface force and the thrust variation force to the superstructure, whose information may not be analogized from the conventional free and forced vibration analysis for ship structure. Hence, it is concluded that the structural intensity analysis can be usefully applied for making a proper countermeasures against troublesome ship structure vibration expected by the conventional analysis.

\section{ACKNOWLEDGEMENT}

This study is supported by Advanced Ship Engineering Research Center of the National Research Foundation of Korea.

\section{REFERENCES}

Alfredsson, K.S. Josefson, B.L. and Wilson, M.A., 1996. Use of the energy flow concept in vibration design. Journal of AIAA, 34(6), pp. 1250-1255.

Fahy, F.J. and Pierri, R., 1977. Application of cross-spectral density to a measurement of vibration power flow between connected plates. Journal of the Acoustical Society of America, 62(5), pp.1297-1298.

Gavric, L. and Pavic, G., 1993. A finite element method for computation of structural intensity by the normal mode approach. Journal of Sound and Vibration, 164(1), pp.29-43.

Hambric, S.A., 1990. Power flow and mechanical intensity calculations in structural finite element analysis. ASME Journal of Vibration and Acoustics, 112, pp.542-549.

Kim, B.H., 2006. A study on the low vibration design of container carrier superstructure using the structural intensity analysis. Master thesis, Pusan National University, Korea.

Lee, D.H. and Cho, D.S., 2001. Structural intensity analysis of local ship structures using finite element method. Journal of the Society of Naval Architects of Korea, 38(3), pp. 62-73.

Linjama, J. and Lahti, T., 1992. Estimation of bending wave intensity in beams using the frequency response technique. Journal of Sound and Vibration, 153(1), pp.21-36.

MSC/Nastran, 1996. MSC/Patran-PAT304 (PCL and Customization), Macneal-Schwendler Co.

Noiseux, D.U., 1970. Measurement of power flow in uniform beams and plates. Journal of the Acoustical Society of America, 47(1), pp. 238-247.

Pascal, J.C. Carniel, X. and Li, J.F., 2006. Characterisation of a dissipative assembly using structural intensity measurements and energy conservation equation. Mechanical Systems and Signal Processing, 20, pp. 1300-1311.

Pavic, G., 1976. Measurement of structure borne wave intensity, Part I: Formulation of the methods. Journal of Sound and Vibration, 49(2), pp. 221-230.

Saijyou, K. and Yoshikawa, S., 1996. Measurement of structural and acoustic intensities using near-field acoustical holography. Journal of Applied Physics of Japan, 35, pp.3167-3174.

Sitton, G. 1997. MSC/Nastran Basic Dynamic Analysis User's Guide, Macneal-Schwendler Co.

Verheij, J.W., 1980. Cross spectral density methods for measuring structure borne power flow on beams and pipes. Journal of Sound and Vibration, 70(1), pp.133-139.

Xu, W. and Koss, L.L., 1995, Frequency response functions for structural intensity, Part I: Theory. Journal of Sound and Vibration, 185(2), pp. 299-334.

Xu, X.D., Lee, H.P. and Lu, C., 2004. The structural intensities of composite plates with a hole. Composite Structures, 65, pp. 493-498.

$\mathrm{Xu}$, X.D. Lee, H.P. Wang, Y.Y. and Lu, C., 2004. The energy flow analysis in stiffened plates of marine structures. Thin-Walled Structures, 42, pp. 979-994. 